\title{
Prognostic Significance of Pretreatment Lymphocyte-to- Monocyte Ratio in Patients with Tongue Cancer
}

\author{
KOHEI FURUKAWA, GORO KAWASAKI, TOMOFUMI NARUSE and MASAHIRO UMEDA \\ Department of Clinical Oral Oncology, \\ Nagasaki University Graduate School of Biomedical Sciences,Sakamoto, Japan
}

\begin{abstract}
Background/Aim: Low pre-operative lymphocyteto-monocyte ratio (LMR) is associated with worse outcomes in several malignancies. The aim of this study was to determine the prognostic value of LMR in tongue cancer. Materials and Methods: A total of 103 patients with pathologically-proven tongue cancer were retrospectively analyzed. The peripheral LMR and the ratio of CD8-positive to CD14-positive $\left(\mathrm{CD}^{+} / \mathrm{CD} 14^{+}\right)$tumor-infiltrating cells were determined by immunohistochemical staining. Receiver operating characteristic curve analysis, log-rank test, and Cox proportional hazards regression models were used for statistical analysis. Results: There was a significant difference in overall survival (OS) between low LMR and high LMR, and low CD8 $8^{+} / \mathrm{CD} 14^{+}$tumor-infiltrating cells and high $\mathrm{CD}^{+} / \mathrm{CD} 14^{+}$tumor infiltrating cells. For the clinical analysis, multivariate analysis showed that clinical ocular inspection type and low LMR were independent predictors for poor OS. Concerning the immunohistochemical analysis, monocyte count was independent predictor of poor OS. Conclusion: Pre-operative LMR and $C D 8^{+} / C D 14^{+}$ tumor-infiltrating cells serve as independent prognostic biomarkers.
\end{abstract}

Oral cancer, including tongue cancer, is the most common form of head and neck cancer (1). Survival of oral cancer patients mainly depends on the stage of the disease. More than $50 \%$ of patients with oral cancer have advanced disease at the time of diagnosis $(1,2)$. However, the survival rates have improved due to new cytotoxic drugs introduced in the last decade.

Lymphocytes play a fundamental role in most immune system mechanisms aimed at identifying and destroying

Correspondence to: Dr. Goro Kawasaki, Department of Clinical Oral Oncology, Nagasaki University Graduate School of Biomedical Sciences, 1-7-1, Sakamoto, Nagasaki, 852-8588, Japan. Tel: +81 958497696, Fax: +81 958497700, e-mail: gkawa@nagasaki-u.ac.jp

Key Words: Tongue cancer, lymphocyte-to-monocyte ratio, prognosis. cancer cells (3). Patients with cancer are known to have abnormalities in T-cell and B-cell counts (4). The microenvironment of oral cancer is characterized by imbalanced cytokine profile, favoring immunosuppressive over stimulatory cytokines (5). It is known that systemic inflammatory responses play important roles in both the development of human cancers and the spread of metastatic tumors $(6,7)$. Several markers of systemic inflammation, including neutrophil, lymphocyte, monocyte, and platelet count, have been used as prognostic indicators $(6,8)$. These markers of systemic immune responses can be measured easily, reproducibly, and inexpensively.

The circulating blood lymphocyte-to-monocyte ratio (LMR) is an indicator of systemic inflammation that can be measured by a simple, inexpensive, and reproducible test (9). Recent research has shown that the absolute count of lymphocyte was independently correlated with the survival of patients with several malignancies $(9,10)$. Other studies demonstrated that a low LMR was associated with worse overall survival (OS) in patients with bladder cancer and pancreatic cancer $(11,12)$.

Among clinical and experimental studies on head and neck cancer, few have included the measurement of immune responses (13). The failure to develop an accurate tumor model that mimics the host and tumor environment, along with the innate heterogeneity of head and neck cancer, may limit the clinical implications of experimental studies.

The present study was designed to determine the prognostic significance of preoperative LMR in patients with tongue cancer. Furthermore, an immunohistochemical study of LMR was performed to determine the association between the ratio of $\mathrm{CD} 8$-positive to $\mathrm{CD} 14$-positive $\left(\mathrm{CD}^{+} / \mathrm{CD} 14^{+}\right)$ tumor infiltrating cells around the cancer cells and clinicopathological factors of the patients.

\section{Materials and Methods}

Patients and collection of the data. The medical records of 103 patients with pathologically proven tongue cancer, diagnosed between April 2001 and December 2015, were retrospectively 
analyzed. All patients received surgical treatment for the tongue cancer, but had not received any prior treatment. Data from medical records on routine laboratory measurements of white blood cells performed prior to the onset of treatment including the counts of lymphocytes and monocytes were retrospectively collected. The tumor stage was classified according to the TNM classification of the International Union Against Cancer (14). In addition, data on age at diagnosis, gender, and pretreatment of tumor staging were also collected. The status of patients (alive/dead) at the end of 5 years from the date of diagnosis was retrieved from medical records.

Receiving operating characteristic (ROC) curve analysis to select the most appropriate cut-off point for the counts of LMR was performed to stratify patients at high risk of malignancy-related death. The score at the point with both maximum sensitivity and specificity was selected as the best cut-off value. In survival analysis, OS time was defined as time from diagnosis until death; the follow-up of patients still alive was censored at their latest date of follow-up.

Immunohistochemistry. Paraffin-embedded sections were obtained from biopsy specimens from 103 patients. The histological differentiation of tumors was defined according to the WHO classification (15), and the invasive grade was assessed using the Yamamoto-Kohama (YK) mode of invasion (16). Deparaffinized sections in xylene were soaked in $10 \mathrm{mmol} / \mathrm{l}$ citrate buffer ( $\mathrm{pH}$ 6.0) and placed in an autoclave at $121^{\circ} \mathrm{C}$ for $5 \mathrm{~min}$ for antigen retrieval. Endogenous peroxidase was blocked by incubation with $0.3 \% \mathrm{H}_{2} \mathrm{O}_{2}$ in methanol for $30 \mathrm{~min}$. Immunohistochemical staining was performed using an Envision system (DAKO, Glostrup, Denmark). The primary antibodies used were anti-CD8 (1:250) and anti-CD14 (1:500) (Abcam, Cambridge, UK). Results were evaluated by calculating the immunohistochemically-positive cells around the cancer cell nest, which was selected at three points at random. $\mathrm{CD}^{+} / \mathrm{CD} 14^{+}$tumor infiltrating cells was calculated from the ratio of lymphocyte counts and monocyte counts, and cut-off points were detected by ROC analysis.

Statistical analysis. Survival curves were generated by the KaplanMeier method and were compared using the log-rank test. The relationship between LMR and clinical factors was assessed using Fischer's exact test. The Cox proportional hazards model was applied for univariate and multivariate analysis to identify prognostic factors. All $p$-values $<0.05$ were considered statistically significant. All statistical analyses were performed with EZR (Saitama Medical Center, Jichi Medical University, Saitama, Japan), which is a graphical user interface for $\mathrm{R}$ (The $\mathrm{R}$ Foundation for Statistical Computing Vienna, Austria) (17). More precisely, it is a modified version $\mathrm{R}$ commander designed to add statistical functions used in biostatistics.

\section{Results}

The median age of patients was 63 years (range 26-92), and the percentage of males and females were $53.8 \%$ and $46.2 \%$, respectively. Out of the 103 patients, 87 (84.5\%) were diagnosed at early stages (I and II) and 16 (15.5\%) patients were at late stages (III and IV). The 5-year OS of the cohort was $84.9 \%$.

The mean value of peripheral blood lymphocytes was $1.79 \times 10^{9}$ cells $/ 1\left(\right.$ range $\left.=0.55-4.79 \times 10^{9}\right)$, and mean value of
Table I. Correlation between peripheral blood LMR and clinical features.

\begin{tabular}{|c|c|c|c|}
\hline \multirow[t]{2}{*}{ Variable } & \multicolumn{2}{|c|}{ LMR } & \multirow[t]{2}{*}{$p$-Value } \\
\hline & $\leq 4.29$ & $>4.29$ & \\
\hline \multicolumn{4}{|l|}{ Gender } \\
\hline Male & 34 & 21 & 0.135 \\
\hline Female & 37 & 11 & \\
\hline \multicolumn{4}{|l|}{ Age } \\
\hline$\leq 63$ & 33 & 21 & 0.086 \\
\hline$>63$ & 38 & 11 & \\
\hline \multicolumn{4}{|c|}{$\mathrm{cT}$ classification } \\
\hline $\mathrm{T} 1, \mathrm{~T} 2$ & 68 & 27 & 0.104 \\
\hline $\mathrm{T} 3, \mathrm{~T} 4$ & 3 & 5 & \\
\hline \multicolumn{4}{|c|}{$\mathrm{cN}$ classification } \\
\hline No & 65 & 25 & 0.104 \\
\hline $\mathrm{N} 1, \mathrm{~N} 2$ & 6 & 7 & \\
\hline \multicolumn{4}{|c|}{ Clinical stage } \\
\hline I, II & 64 & 23 & 0.036 \\
\hline III, IV & 7 & 9 & \\
\hline \multicolumn{4}{|c|}{ Alcohol status } \\
\hline No & 45 & 20 & 1 \\
\hline Yes & 26 & 12 & \\
\hline \multicolumn{4}{|c|}{ Smoking status } \\
\hline No & 51 & 22 & 0.816 \\
\hline Yes & 20 & 10 & \\
\hline \multicolumn{4}{|c|}{ Clinical inspection } \\
\hline External & 36 & 11 & 0.14 \\
\hline Invasive & 35 & 21 & \\
\hline \multicolumn{4}{|c|}{ Survival status (DSS) } \\
\hline Alive & 66 & 24 & 0.021 \\
\hline Dead & 5 & 8 & \\
\hline \multicolumn{4}{|c|}{ Survival status (OS) } \\
\hline Alive & 65 & 17 & $<0.001$ \\
\hline Dead & 6 & 15 & \\
\hline
\end{tabular}

LLMR, Lymphocyte-to-monocyte ratio; cT, clinical T; cN, clinical N; DSS, disease specific survival; OS, overall survival.

peripheral blood monocyte was $0.32 \times 10^{9}$ cells $/ 1$ (range $=0.04$ $\left.0.88 \times 10^{9}\right)$. The cut-off value of LMR was determined, and using the LMR cut-off point of 4.29, all patients were divided into either high $(\mathrm{LMR} \geq 4.29)$ or low $(\mathrm{LMR}<4.29)$ groups. Thereafter, clinical factors were analyzed against LMR (high LMR vs. low LMR) (Table I). Regarding the clinical stage, as well as the survival rate, including both OS and disease-specific survival, results showed significant differences between high- and low-LMR groups (Table I, Figure 1). Moreover, a univariate analysis of clinical features, including gender, age, alcohol status, smoking, T classification, $\mathrm{N}$ classification, clinical stage, clinical ocular inspection type, monocyte count, lymphocyte count, and LMR, and their association with OS was performed (Table II). The analysis revealed that gender, $\mathrm{T}$ classification, $\mathrm{N}$ classification, clinical stage, clinical ocular inspection type, and LMR were significantly associated with OS. The 

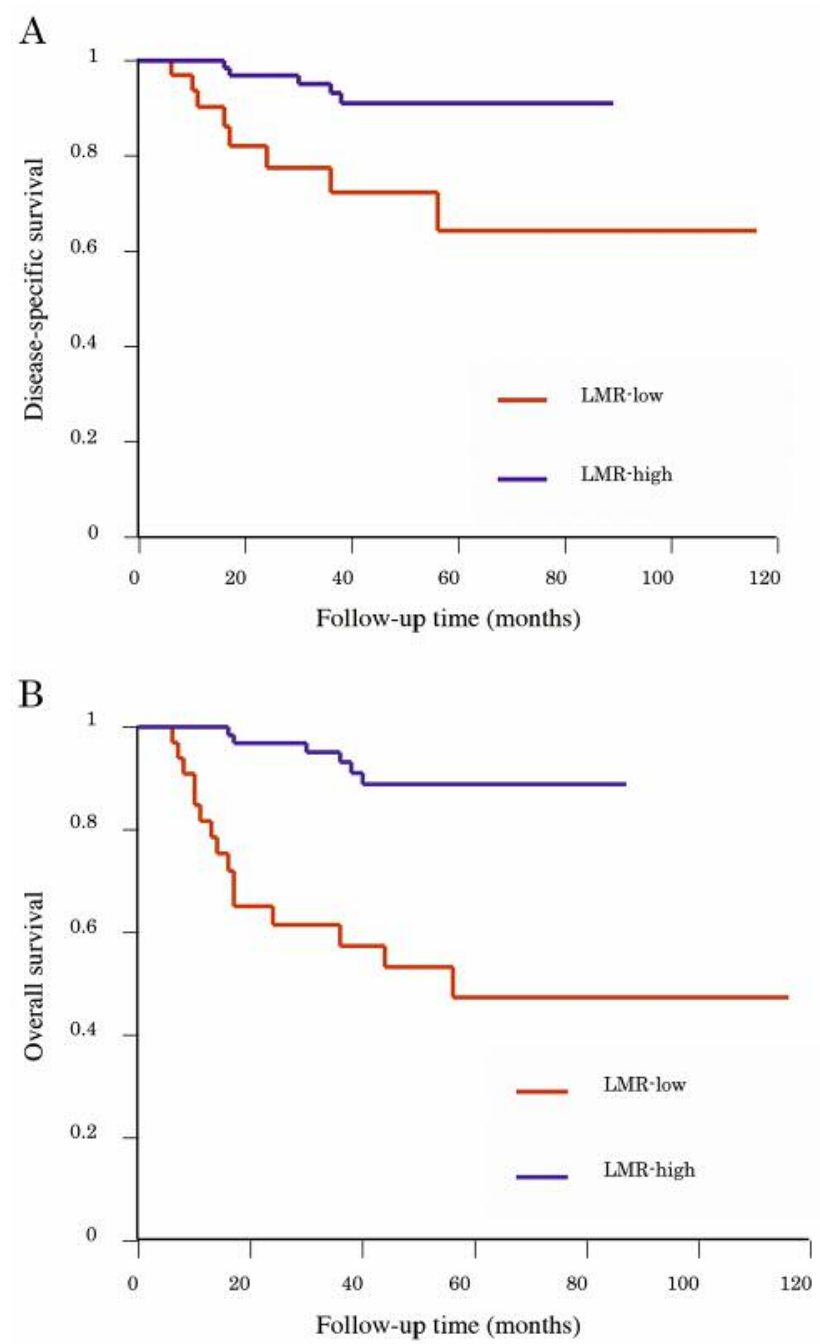

Figure 1. Kaplan-Meier survival curve. Significant differences in disease-specific survival and overall survival were observed between low lymphocyte-to-monocyte ratio (LMR) and high LMR groups. There was significant difference between low-LMR and high-LMR groups.

aforementioned clinical factors were also included in a multivariate analysis, which showed that clinical ocular inspection type and low LMR were independent predictors of poor OS in patients with tongue cancer (Table II).

Immunohistochemical findings. The mean labeling index of lymphocytes was 36.3 (range $=0-86$ ), and mean labeling index of monocytes was 21.3 (range=3-48) (Figure 2). The cut-off value of $\mathrm{CD}^{+} / \mathrm{CD} 14^{+}$ratio was determined at 1.27 by $\mathrm{ROC}$ curves, and using this cut-off point patients were divided into either high- $\left(\mathrm{CD}^{+} / \mathrm{CD} 14^{+} \geq 1.27\right)$ or low-CD8 ${ }^{+} / \mathrm{CD} 14^{+}$ $\left(\mathrm{CD}^{+} / \mathrm{CD} 14^{+}<1.27\right)$ groups. Clinicopathological factors were analyzed against $\mathrm{CD} 8^{+} / \mathrm{CD} 14^{+}$(high $\mathrm{CD}^{+} / \mathrm{CD} 14^{+}$vs. low

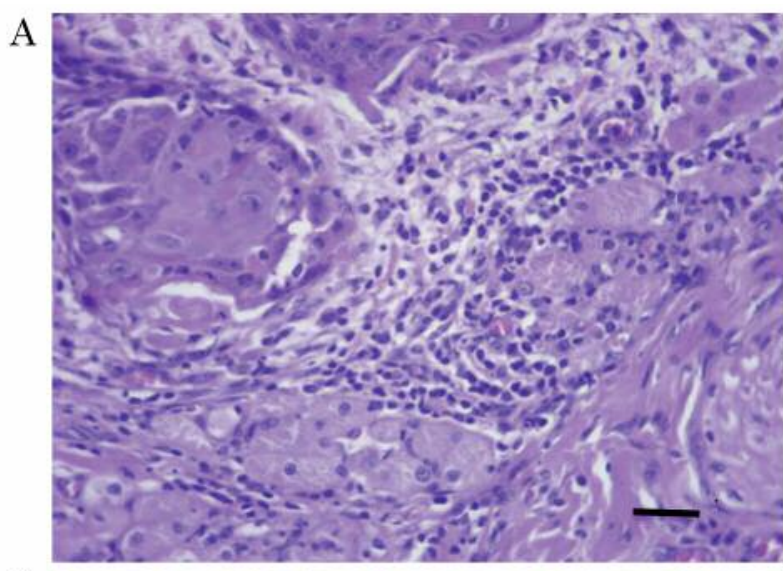

B

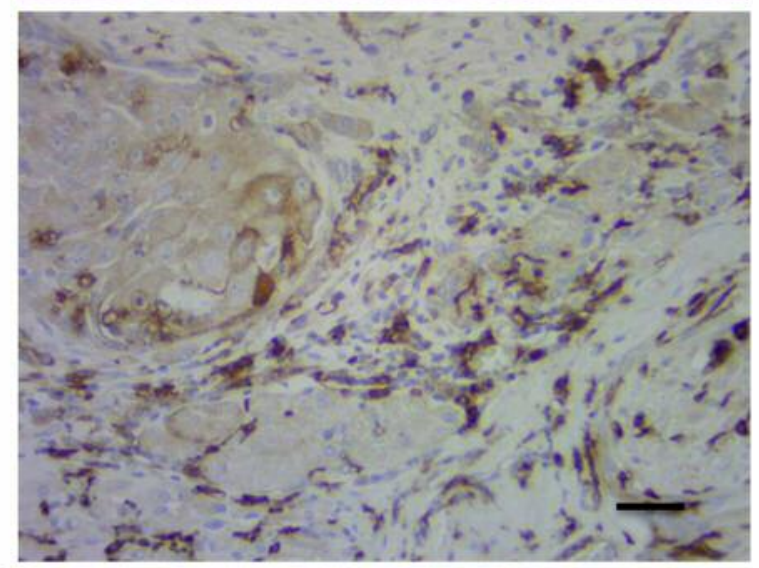

C

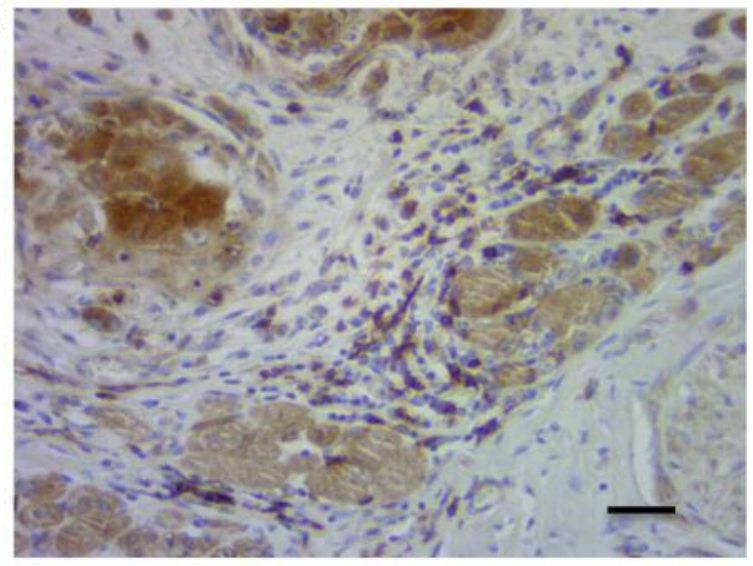

Figure 2. Hematoxylin-eosin staining (HE) and immunohistochemicallydetermined expression levels of CD8 and CD14. (A: HE, B: CD8, C: CD14) $\mathrm{Bar}=20 \mu \mathrm{m}$.

$\mathrm{CD}^{+} / \mathrm{CD} 14^{+}$) (Table III). Significant differences were observed concerning the mode of invasion, perineural invasion, and depth of invasion between low- and high$\mathrm{CD}^{+} / \mathrm{CD} 14^{+}$groups. In relation to the survival rate, in terms of OS, there was a significant difference between high $\mathrm{CD}^{+} / \mathrm{CD} 14^{+}$and low $\mathrm{CD}{ }^{+} / \mathrm{CD} 14^{+}$(Figure 3 ). 
Table II. Univariate and multivariate analysis of clinical factors associated with overall survival.

\begin{tabular}{|c|c|c|c|c|}
\hline \multirow[t]{3}{*}{ Variable } & \multicolumn{4}{|c|}{ OS } \\
\hline & \multicolumn{2}{|c|}{ Univariate analysis } & \multicolumn{2}{|c|}{ Multivariate analysis } \\
\hline & $\mathrm{HR}(95 \% \mathrm{CI})$ & $p$-Value & $\operatorname{HR}(95 \% \mathrm{CI})$ & $p$-Value \\
\hline Gender & & 0.015 & & 0.189 \\
\hline Male & & & & \\
\hline Female & $3.5(1.28-9.59)$ & & $2.45(0.64-9.35)$ & \\
\hline Age & & 0.56 & & 0.316 \\
\hline$<63$ & & & & \\
\hline$\geq 63$ & $1.3(0.55-3.07)$ & & $1.79(0.57-5.62)$ & \\
\hline Alcohol status & & 0.243 & & 0.876 \\
\hline No & & & & \\
\hline Yes & $1.67(0.91-3.94)$ & & $1.10(0.32-3.80)$ & \\
\hline Smoking status & & 0.931 & & 0.605 \\
\hline No & & & & \\
\hline Yes & $1.04(0.40-2.70)$ & & $0.70(0.18-2.71)$ & \\
\hline cT classification & & $p<0.001$ & & 0.812 \\
\hline $\mathrm{T} 1+\mathrm{T} 2$ & & & & \\
\hline $\mathrm{T} 3+\mathrm{T} 4$ & $5.68(2.18-14.8)$ & & $1.22(0.24-6.19)$ & \\
\hline $\mathrm{cN}$ classification & & 0.004 & & 0.977 \\
\hline No & & & & \\
\hline $\mathrm{N} 1+\mathrm{N} 2+\mathrm{N} 3$ & $3.88(1.56-9.63)$ & & $1.03(0.16-6.45)$ & \\
\hline Clinical Stage & & $p<0.001$ & & 0.546 \\
\hline $\mathrm{I}+\mathrm{II}$ & & & & \\
\hline III+IV & $4.76(2.00-11.32)$ & & $2.05(0.20-20.99)$ & \\
\hline Clinical ocular inspection type & & 0.003 & & 0.006 \\
\hline External & & & & \\
\hline Internal & $9.47(2.21-40.7)$ & & $11.97(2.03-70.47)$ & \\
\hline $\begin{array}{l}\text { Peripheral monocyte count } \\
<0.32\end{array}$ & & 0.518 & & 0.204 \\
\hline$\geq 0.32$ & $1.32(0.56-3.12)$ & & $1.89(0.71-5.07)$ & \\
\hline $\begin{array}{l}\text { Peripheral lymphocyte count } \\
<1.79\end{array}$ & & 0.264 & & 0.485 \\
\hline$\geq 1.79$ & $1.65(0.68-3.99)$ & & $0.65(0.19-2.20)$ & \\
\hline Peripheral blood LMR & & $<0.001$ & & 0.002 \\
\hline$<4.29$ & & & & \\
\hline$\geq 4.29$ & $0.14(0.05-0.36)$ & & $0.17(0.06-0.53)$ & \\
\hline
\end{tabular}

OS, Overall survival; HR, hazard ratio; CI, confidence interval; cT, clinical T; cN, clinical N; LMR, lymphocyte-to-monocyte ratio.

Univariate and multivariate analyses were performed to examine the association between OS and pathological factors, including histological grade, local relapse, depth of invasion, pathological $\mathrm{T}$ classification (pT), pathological $\mathrm{N}$ classification $(\mathrm{pN})$, perineural invasion, mode of invasion, late lymph node metastasis, CD8-positive lymphocyte count, CD-14-positive monocyte count, and $\mathrm{CD}^{+} / \mathrm{CD} 14^{+}$(Table IV). Univariate analysis revealed that the depth of invasion, $\mathrm{pT}, \mathrm{pN}$, perineural invasion, mode of invasion, late lymph node metastasis, CD14-positive monocyte count, and $\mathrm{CD}^{+} / \mathrm{CD} 14^{+}$were associated with OS. Moreover, according to the multivariate analysis, high monocyte counts were independent predictors for poor OS in patients with tongue cancer (Table IV).

\section{Discussion}

Total and differential white blood cell counts have been historically used as a marker of infection and inflammation (9). Recently, systemic inflammation has been recognized to correlate with tumor progression, and inflammatory markers have been reported to be useful for predicting prognosis (1820). Although a link between inflammation and cancer has been known for more than a century, a strong association between pretreatment peripheral inflammatory cells and prognosis in different kinds of cancer has recently been revealed (21).

LMR is an inflammatory marker that has been reported to correlate with survival in patients with various types of 
Table III. Correlation between the CD8-positive to CD14-positive $(C D 8+/ C D 14+)$ tumor-infiltrating cell ratio and pathological features.

\begin{tabular}{|c|c|c|c|}
\hline \multirow[t]{2}{*}{ Variable } & \multicolumn{2}{|c|}{$\mathrm{CD}^{+} / \mathrm{CD} 14^{+}$} & \multirow[t]{2}{*}{$p$-Value } \\
\hline & $\geq 1.27$ & $<1.27$ & \\
\hline \multicolumn{4}{|l|}{ pT classification } \\
\hline $\mathrm{T} 1, \mathrm{~T} 2$ & 68 & 27 & 0.013 \\
\hline $\mathrm{T} 3, \mathrm{~T} 4$ & 2 & 6 & \\
\hline \multicolumn{4}{|l|}{$\mathrm{pN}$ classification } \\
\hline No & 63 & 24 & 0.039 \\
\hline $\mathrm{N} 1, \mathrm{~N} 2$ & 7 & 9 & \\
\hline \multicolumn{4}{|l|}{ Histological grade } \\
\hline Well & 67 & 32 & 1 \\
\hline Moderate, poor & 3 & 1 & \\
\hline \multicolumn{4}{|l|}{ Mode of invasion } \\
\hline $1,2,3$ & 61 & 21 & 0.009 \\
\hline $4 \mathrm{C}, 4 \mathrm{D}$ & 9 & 12 & \\
\hline \multicolumn{4}{|c|}{ Perineural invasion } \\
\hline No & 57 & 20 & 0.03 \\
\hline Yes & 61 & 29 & \\
\hline \multicolumn{4}{|l|}{ Local relapse } \\
\hline No & 9 & 4 & 1 \\
\hline Yes & 26 & 12 & \\
\hline \multicolumn{4}{|c|}{ Late lymphnode metastasis } \\
\hline No & 59 & 20 & 0.012 \\
\hline Yes & 11 & 13 & \\
\hline \multicolumn{4}{|l|}{ Depth of invasion } \\
\hline$<4 \mathrm{~mm}$ & 39 & 12 & 0.091 \\
\hline$\geq 4 \mathrm{~mm}$ & 31 & 21 & \\
\hline \multicolumn{4}{|c|}{ Survival status (DSS) } \\
\hline Alive & 64 & 26 & 0.109 \\
\hline Dead & 6 & 7 & \\
\hline \multicolumn{4}{|c|}{ Survival status (OS) } \\
\hline Alive & 61 & 21 & 0.009 \\
\hline Dead & 9 & 12 & \\
\hline
\end{tabular}

pT, Pathological T; pN, pathological N; DSS, disease specific survival; OS, overall survival.

cancer $(12,18-20,22)$. However, there have been few reports concerning clinicopathological factors and prognosis in relation to oral cancer. To the best of our knowledge, this is the first study to assess the clinicopathological and prognostic significance of peripheral $\mathrm{LMR}$ and $\mathrm{CD} 8^{+} / \mathrm{CD} 14^{+}$ tumor infiltrating cells in oral cancer patients.

Lymphocytes play an important role in the activation of antitumor immune responses, as well as destruction of residual cancer cells and micrometastases after complete resection (23). It has been proposed that tumor-infiltrating lymphocytes of the host significantly contribute to the efficacy of anticancer treatments, since they may lead cancer cells to death by presenting tumor-associated antigens to immune cells, in response to chemoradiation therapy $(22,24)$. In particularly, higher lymphocyte counts have been reported to predict a better response to operative chemoradiation
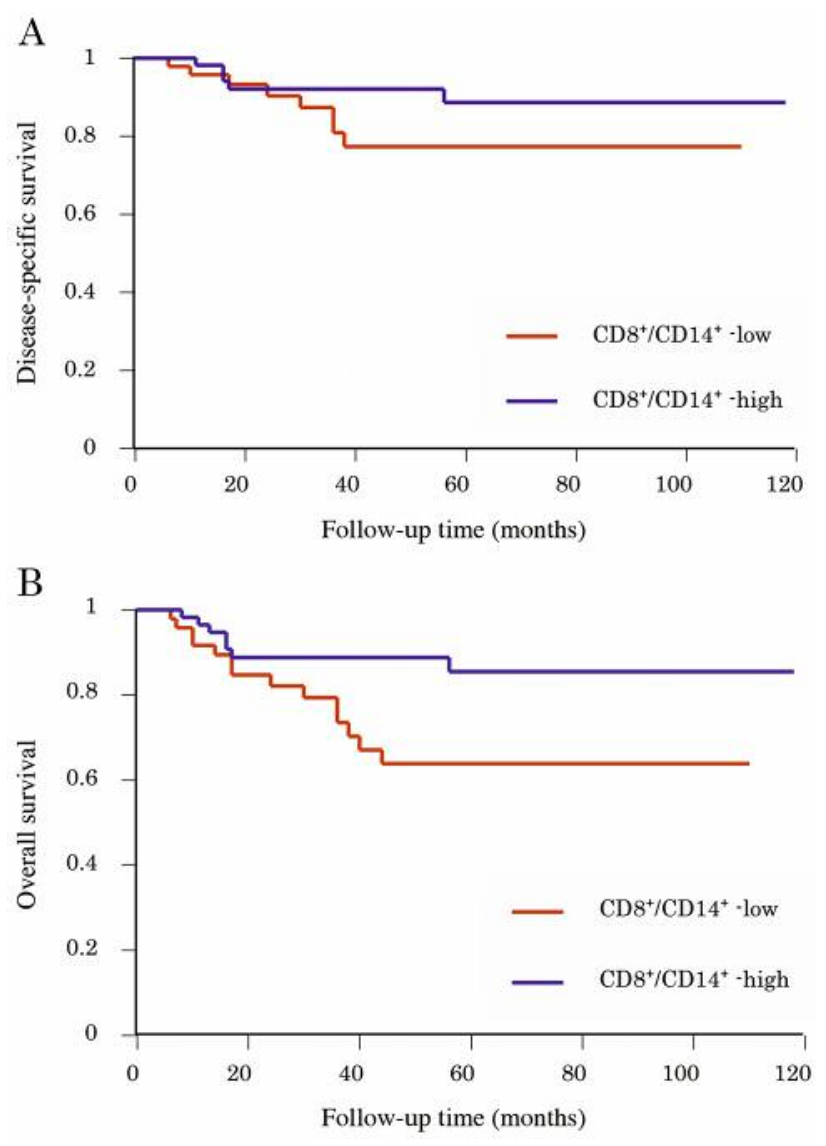

Figure 3. Kaplan-Meier survival curve. Significant differences in disease-specific survival and overall survival were present between low ratio of CD8-positive to CD14-positive $\left(\mathrm{CD}^{+} / \mathrm{CD14^{+ }}\right)$ and high $C D 8^{+} / C D 14^{+}$groups. There was a significant difference in overall survival between low- $C D 8^{+} / C D 14^{+}$and high- $C D 8^{+} / C D 14^{+}$groups.

therapy in rectal cancer (25). Recently, in laryngeal cancer, Dewyer et al. (26) reported that higher concentrations of CD4-positive lymphocytes predicted a response to induction chemotherapy.

A large amount of accumulated evidence indicates that CD4-positive $\mathrm{T}$ cells have a pivotal role in generating and maintaining anti-tumor immune responses through their interactions with cytotoxic T lymphocytes, B lymphocytes, macrophages, and NK cells (3). Therefore, decreased number of lymphocytes is considered to be responsible for an insufficient immunological reaction to the tumor, thus enabling tumor progression and metastasis.

On the other hand, monocytes play an important role in tumor progression and metastasis $(6,27)$. Monocytes secrete various proinflammatory cytokines, such as interleukin (IL)-1, IL-6, IL-10, and tumor necrosis factor- $\alpha$, which have 
Table IV. Univariate and multivariate analysis of pathological factors associated with overall survival.

\begin{tabular}{|c|c|c|c|c|}
\hline \multirow[t]{3}{*}{ Variable } & \multicolumn{4}{|c|}{ OS } \\
\hline & \multicolumn{2}{|c|}{ Univariate analysis } & \multicolumn{2}{|c|}{ Multivariate analysis } \\
\hline & $\operatorname{HR}(95 \% \mathrm{CI})$ & $p$-Value & $\operatorname{HR}(95 \% \mathrm{CI})$ & $p$-Value \\
\hline $\begin{array}{l}\text { Histological grade } \\
\text { Well }\end{array}$ & & 0.822 & & 0.707 \\
\hline Moderate, poor & $1.26(0.17-9.38)$ & & $1.87(0.15-16.6)$ & \\
\hline $\begin{array}{l}\text { Local relapse } \\
\text { No }\end{array}$ & & 0.821 & & 0.733 \\
\hline Yes & $1.15(0.34-3.92)$ & & $1.29(0.30-5.48)$ & \\
\hline $\begin{array}{l}\text { Depth of invasion } \\
\text { No }\end{array}$ & & 0.006 & & 0.306 \\
\hline Yes & $4.63(1.56-13.8)$ & & $2.20(0.49-9.99)$ & \\
\hline $\begin{array}{l}\mathrm{pT} \text { classification } \\
\mathrm{T} 1, \mathrm{~T} 2\end{array}$ & & $p<0.001$ & & 0.838 \\
\hline $\mathrm{T} 3, \mathrm{~T} 4$ & $6.74(2.55-17.8)$ & & $1.18(0.25-5.56)$ & \\
\hline $\begin{array}{l}\mathrm{pN} \text { classification } \\
\text { N0 }\end{array}$ & & $p<0.001$ & & 0.274 \\
\hline $\mathrm{N} 1, \mathrm{~N} 2, \mathrm{~N} 3$ & $4.55(1.91-10.8)$ & & $2.50(0.48-13.0)$ & \\
\hline $\begin{array}{l}\text { Perineural invasion } \\
\text { No }\end{array}$ & & 0.005 & & 0.456 \\
\hline Yes & $3.41(0.45-8.04)$ & & $0.58(0.14-2.42)$ & \\
\hline $\begin{array}{l}\text { Mode of invasion } \\
1,2,3\end{array}$ & & $p<0.001$ & & 0.579 \\
\hline $4 \mathrm{C}, 4 \mathrm{D}$ & $4.17(1.76-9.87)$ & & $1.34(0.48-3.77)$ & \\
\hline $\begin{array}{l}\text { Late lymph node metastasis } \\
\text { No }\end{array}$ & & $p<0.001$ & & 0.06 \\
\hline Yes & $4.76(2.01-11.3)$ & & $2.73(0.94-7.89)$ & \\
\hline $\begin{array}{l}\text { CD14-positive cells } \\
<21\end{array}$ & & 0.028 & & 0.041 \\
\hline$\geq 21$ & $0.35(0.13-0.90)$ & & $0.27(0.08-0.95)$ & \\
\hline $\begin{array}{l}\text { CD8-positive cells } \\
<36\end{array}$ & & 0.02 & & 0.552 \\
\hline$\geq 36$ & $0.32(0.13-0.84)$ & & $1.54(0.37-6.30)$ & \\
\hline $\begin{array}{l}\mathrm{CD}^{+} / \mathrm{CD}_{14}+ \\
<1.27\end{array}$ & & 0.004 & & 0.105 \\
\hline$\geq 1.27$ & $0.28(0.12-0.66)$ & & $0.28(0.06-1.30)$ & \\
\hline
\end{tabular}

pT, Pathological T; pN, pathological N; p-Monocyte, pathological monocyte; p-Lymphocyte, pathological lymphocyte; HR, hazard ratio; CI, confident interval; $\mathrm{CD} 8{ }^{+} / \mathrm{CD} 14^{+}, \mathrm{CD} 8$-positive to $\mathrm{CD} 14$-positive tumor-infiltrating cell ratio.

been associated with shorter survival and worse prognosis in malignances $(28,29)$. Furthermore, tumor-associated macrophages, which are derived from circulating monocytes, suppress adaptive immunity and promote angiogenesis, invasion, migration, and tumor growth $(30,31)$. The study conducted by Tsai et al. showed that the peripheral total white blood cell count, monocyte, and neutrophil to lymphocyte ratio increased with advancement of clinical stage of the oral cancer patients, while the lymphocyte count decreased (32). The monocyte count was also increased in patients with lymph node metastasis. Moreover, the pretreatment circulating monocyte count was an independent prognostic factor for worse oral squamous cell carcinoma-specific survival (32).
As mentioned above, the LMR reflects both the immune status of the host and the degree of tumor progression. Since both a low lymphocyte count and high monocyte count reflect insufficient anti-tumor immunity and an elevated tumor burden, a low LMR is associated with a poorer prognosis. Studies on patients with various types of malignancies, including urothelial (9), bladder (6), colorectal (18), oropharyngeal (25), and breast cancer (33) have reported that low LMR is associated with poor prognosis, which is consistent with the present results on tongue cancer patients.

Ong et al. (13) analyzed the association of peripheral LMR and platelet-to-lymphocyte ratio with the disease outcome in 133 cases of early tongue cancer (T1N0 and T2N0). They 
concluded that low pretreatment LMR and high platelet-tolymphocyte ratio predicted poor survival in the studied population (13). The present cohort comprised 87 early tongue cancer cases $(84.5 \%)$ and our results were in accordance with findings by Ong et al., suggesting close follow-up for the low-LMR group, even after radical resection with clear margin.

Further immunohistochemical study demonstrated that high monocyte counts were independent predictors for poor OS of tongue cancer. In the present study, we used CD14 and CD8 as markers for monocytes and T-lymphocytes, respectively. Most $\mathrm{CD} 14^{+}$cells and $\mathrm{CD}^{+}$cells were located in the cancer stroma, whereas only few infiltrated into the cancer cell nests. Nevertheless, high $\mathrm{CD} 14^{+}$cells were independent predictors for poor OS.

The monocytes, with high level of CD14 but not CD16, differentiate into M1 macrophages, which play proinflammatory and tumor suppressive roles (34). In contrast, the monocytes, with a high level of CD14 and low CD16, differentiate into M2 macrophage, which play immunosuppressive and tumor-promoting roles (35). Moreover, Zhu et al. (36) showed that the LMR, $\mathrm{CD} 45 \mathrm{RO} / \mathrm{CD} 68$ ratio, and CD8/CD68 ratio were significantly associated with both overall survival and disease-free survival in esophageal squamous cell carcinoma. Hence, further investigations concerning another markers such as CD16, $\mathrm{CD} 45 \mathrm{RO}$ and $\mathrm{CD} 68$, are required in tongue cancer.

In consideration of our results, we suggest that LMR and monocytes may be useful to predict prognosis in tongue cancer patients. Grimm et al. showed that neutrophilia leukocytosis, and monocytosis were associated with advanced tumor stages. Their study also revealed a link between LMR, neutrophil-to-lymphocyte ratio, and plateletto-lymphocyte ratio, which might be used in monitoring the clinical course of oral cancer patients (23).

Many studies have declared that circulating hematological parameters might be prognostic factors of oral cancer, but the mechanism underpinning this phenomenon remains unclear $(13,17,21,34)$. Additionally to the analysis of peripheral LMR, herein LMR was immunohistochemically studied as a prognostic factor of tongue cancer. A limitation of this study is that the hematological parameters except LMR have not been determined, hence in the future, we may need to investigate the relationship of other inflammatory markers with the prognosis of tongue cancer.

\section{Conclusion}

Pretreatment peripheral and $\mathrm{CD} 8^{+} / \mathrm{CD} 14^{+}$tumor infiltrating cells were significantly correlated with OS of tongue cancer patients, suggesting that pre-operative LMR should be considered as an independent prognostic biomarker in tongue cancer.

\section{Ethical Approval}

This study was approved by the Ethics Committee of the Nagasaki University Graduate School of Biomedical Sciences (approval no. 18101505).

\section{References}

1 Dovsak T, Ihan A, Didannovic V, Kansky A, Verdenik M and Heren NI: Effect of surgery and radiotherapy on complete blood count, lymphocyte subsets and inflammatory response in patients with advanced oral cancer. BMC cancer 18: 235-244, 2018.

2 Warnakulsuria S: Global epidemiology of oral and oropharyngeal cancer. Oral Oncol 45: 309-316, 2009.

3 Amit M, Yen TC, Liao CT, Chaturuvedi P, Agarwal JP, Kowalski LP, Ebrahimi A, Clark JR, Kreppel M, Zoller J, Fridman E, Bolzoni VA, Shah JP, Binenbaum Y, Patel SG and Gil Z: Improvement in survival of patients with oral cavity squamous cell carcinoma: an international collaboration study. Cancer 119: 4242-4248, 2013

4 Lee JJ, Lin CL, Chen THH, Kok SH, Chang MC and Jeng JH: Changes in peripheral blood lymphocyte phenotypes distribution in patients with oral cancer/oral leukoplakia in Taiwan. Int J Oral Maxillofac Surg 39: 806-814, 2010.

5 Gildener-Leapman N, Ferris RL and Bauman JE: Promising systemic immunotherapies in head and neck squamous cell carcinoma. Oral Oncol 49: 1089-1096, 2013.

6 Yoshida T, Kinoshita H, Yoshida K, Yanishi M, Inui H, Komai Y, Sugi M, Inoue T, Murota T and Matsuda T: A novel risk stratification model, involving preoperative lymphocytemonocyte ratio and standard pathological factors, for overall survival in patients with bladder cancer undergoing radical cystectomy. Jpn J Clin Oncol 45: 1162-1167, 2015.

7 Coussens LM and Werb Z: Inflammation and cancer. Nature 420: 860-867, 2002.

8 Ohno Y, Nakashima J, Ohori M, Gondo T, Hatano T and Tachibana M: Follow-up of neutrophil-to-lymphocyte ratio and recurrence of clear cell renal cell carinoma. J Urol 187: 411-417, 2012.

9 Zhang XK, Yang P, Zhang ZL, Hu WM and Cao Y: Preoperative low lymphocyte-to-monocyte ratio predicts poor clinical outcomes for patients with urothelial carcinoma of the upper urinary tract. Urol J, 2018. doi: 10.22037/uj.v0i0.4120. [Epub ahead of print]

10 Bruckner HW, Lavin PT, Plaxe SC, Storch JA and Livstone EM: Absolute granulocyte, lymphocyte, and moncyte counts. Useful determinants of prognosis for patients with metastatic cancer of the stomach. JAMA 247: 1004-1006, 1982.

11 Temraz S, Mukherji D, Farhat ZA, Nasr R, Charafeddine M, Shahait M, Wehbe MR, Ghaida RA, Gheida IA and Shamseddine A: Preoperative lymphocyte-to-monocyte ratio predicts clinical outcome in patients undergoing radical cystectomy for transitional cell carcinoma of the bladder: a retrospective analysis. BMC Urol 76: 14-19, 2014.

12 Stotz M, Szkandera J, Stojakovic T, Seidel J, Samonigg H, Kornprat P, Schaberl-Moser R, Seggewies F, Hoefler G, Gerger A and Pichler M: The lymphocyte to monocyte ratio in peripheral blood represents a novel prognostic marker in patients with pancreatic cancer. Clin Chem Lab Med 53: 499$506,2015$. 
13 Ong HS, Gokavarapu S, Wang LZ, Tian Z and Zhang CP: Low pretreatment lymphocyte-monocyte ratio and high plateletlymphocyte ratio indicate poor cancer outcome in early tongue cancer. J Oral Maxillofac Surg 75: 1762-1774, 2017.

14 Sobin $\mathrm{LH}$ and Wittekind $\mathrm{CH}$ : International Union Against Cancer: TNM classification of malignant tumours, 5th edn., New York, Wiley, pp. 1-277, 1997.

15 Wahi PN: (WHO) Histological typing of oral and oropharyngeal tumours, 4th edn., Geneva, WHO, pp. 1-28, 1971.

16 Yamamoto K, Kohama G, Sunakawa H, Iwai M and Hiratsuka $\mathrm{H}$ : Mode of invasion, bleomycin sensitivity, and clinical course in squamous cell carcinoma of the oral cavity. Cancer 51: 2175$2180,1983$.

17 Kanda Y: Investigation of the freely available easy-to-use software EZR for medical statistics. Bone Marrow Transplant 48: 452-458, 2013.

18 Shibutani M, Maeda K, Nagahara H, Ohtani H, Sakurai K, Yamazoe S, Kimura K, Toyokawa T, Amano R, Tanaka H, Muguruma K and Hirakawa K: Prognostic significance of the lymphocyte-to-monocyte ratio in patients with metastatic colorectal cancer. World J Gastroenterol 21: 9966-9973, 2015.

19 Shibutani M, Maeda K, Nagahara H, Noda E, Ohtani H, Nishiguchi $\mathrm{Y}$ and Hirakawa K: A high preoperative neutrophilto-lymphocyte ratio is associated with poor survival in patients with colorectal cancer. Anticancer Res 33: 3291-3294, 2013.

20 Maeda K, Shibutani M, Otani H, Nagahara H, Sugano K, Ikeya T, Amano R, Kimura K, Sakurai K, Kubo N, Muguruma K, Tanaka $\mathrm{H}$, Inoue $\mathrm{T}$ and Hirakawa $\mathrm{K}$ : Prognostic value of preoperative inflammation-based prognostic scores in patients with stage IV colorectal cancer who undergo palliative resection of asymptomatic primary tumors. Anticancer Res 33: 5567-5573, 2013.

21 Bobdey S, Ganesh B, Mishra P and Jain A: Role of monocyte count and neutrophil-to-lymphocyte ratio in survival of oral cancer patients. Int Arch Otorhinolaryngol 21: 21-27, 2017.

22 Lee KH, Kim EY, Yun JS, Park YL, Do SI, Chae SW and Park $\mathrm{CH}$ : The prognostic and predictive value of tumor-infiltrating lymphocytes and hematologic parameters in patients with breast cancer. BMC cancer 18: 938-946, 2018

23 Grimm M, Rieth J, Hoefert S, Krimmel M, Rieth S, Teriete P, Kluba S, Biegner T, Munz A and Reinert S: Standardized pretreatment inflammatory laboratory markers and calculated ratios in patients with oral squamous cell carcinoma. Eur Arch Otorhinolaryngol 273: 3371-3384, 2016.

24 Apetoh L, Tesniere A, Ghiringhelli F, Kroemer G and Zitvogel L: Molecular interactions between dying tumor cells and the innate immune system determine the efficacy of conventional anticancer therapies. Cancer Res 68: 4026-4030, 2008.

25 Huang SH, Waldron JN, Milosevic M, Shen X, Ringash J, Su J, Tong L, Perez-Ordonez B, Weinreb I, Bayley AJ, Kim J, Hope A, Cho BC, Giuliani M, Razak A, Goldstein D, Shi W, Liu FF, $\mathrm{Xu}$ W and O'Sullivan B: Prognostic value of pretreatment circulating neutrophils, monocytes, and lymphocytes in oropharyngeal cancer stratified by human papillomavirus status. Cancer 121: 545-555, 2015.
26 Dewyer NA, Wolf GT, Light E, Worden F, Urba S, Eisbruch A, Bradford CR, Chepeha DB, Prince ME, Moyer J and Taylor J: Circulating CD4-positive lymphocyte levels as predictor of response to induction chemotherapy in patients with advanced laryngeal cancer. Head Neck 36: 9-14, 2014.

27 Evani SJ, Prabhu RG, Gnanaruban V and Finol EA: Ramasubramanian AK.mediate metastatic breast tumor cell adhesion to endothelium under flow. FASEB J 27: 3017-3029, 2013.

28 Anand M, Chodda SK, Parikh PM and Nadkarni JS: Abnormal levels of proinflammatory cytokines in serum and monocyte cultures from patients with chronic myeloid leukemia in different stages, and their role in prognosis. Hematol Oncol 16: 143-154, 1998

29 Pollard JW: Tumour-educated macrophages promote tumour progression and metastasis. Nat Rev Cancer 4: 71-78, 2004.

30 Mantovani A, Bottazzi B, Colotta F, Sozzani S and Ruco L: The origin and function of tumor-associated macrophages. Immunol Today 13: 265-270, 1992.

31 Condeelis J and Pollard JW: Macrophages: obligate partners for tumor cell migration, invasion, and metastasis. Cell 124: 263266, 2006.

32 Tsai YD, Wang CP, Chen CY, Lin LW, Hwang TZ, Lu LF, Hsu HF, Chung FM, Lee YJ and Houng JY: Pretreatment circulating monocyte count associated with poor prognosis in patients with oral cavity cancer. Head Neck 36: 947-953, 2014.

33 Cho U, Park HS, Im SY, Yoo CY, Jung JH, Suh YJ and Choi HJ: Prognostic value of systemic inflammatory markers and development of a nomogram in breast cancer. PLoS One 13: e0200936, 2018.

34 Zigmond E, Samia-Grinberg S, Pasmanik-Chor M Brazowski E, Shibolet $\mathrm{O}$, Halpem $\mathrm{Z}$ and Varol $\mathrm{C}$ : Infiltrating monocytederived macrophages and resident Kupffer cells display different ontogeny and functions in acute liver injury. J Immunol 193: 344-353, 2014

35 Lee HW, Choi HJ, Ha SJ, Lee KT and Kwon YG: Recruitment of monocytes/macrophages in different tumor microenvironments. Biochem Biophys Acta 1835: 170-179, 2013.

36 Zhu Y, Li M, Bo C, Liu X, Zhang J, Li Z, Zhao F, Kong L and Yu $\mathrm{J}$ : Prognostic significance of the lymphocyte-to-monocyte ratio and the tumor-infiltrating lymphocyte to tumor-associated macrophage ratio in patients with stage T3NOM0 esophageal squamous cell carcinoma. Cancer Immunol Immunother 66: 343-354, 2017.

37 Yang J, Hsueh CY, Cao W and Zhou L: Pretreatment lymphocyte-to-monocyte ratio as an independent prognostic factor for hypopharyngeal squamous cell carcinoma. Acta OtoLaryngologica 138: 734-740, 2018.

Received October 16, 2018

Revised November 20, 2018

Accepted November 23, 2018 